\title{
O valor de frutas, legumes e verduras comercializadas em feiras livres e sua interface com a Segurança Alimentar e Nutricional (SAN)
}

\author{
Camila Irigonhé Ramos ${ }^{1}$ \\ Evander Eloi Krone ${ }^{2}$ \\ Renata Menasche ${ }^{3}$
}

\begin{abstract}
Resumo
O presente estudo objetivou promover a reflexão sobre a valoração dos alimentos que os feirantes produzem e/ou comercializam, e, além disso, como este processo relaciona-se com a segurança alimentar e nutricional de todos os atores envolvidos no sistema alimentar. Trata-se de uma pesquisa qualitativa, com inspiração etnográfica. Na coleta dos dados realizou-se entrevistas em profundidade e observação participante em feiras orgânicas e convencionais, além de locais de produção de orgânicos, durante os anos de 2013 e 2014 no município de Pelotas/RS e região. Como principais resultados obteve-se que existem nas feiras aqueles que são apenas produtores, os que produzem e revendem e os revendedores, este fato influencia na relação que o feirante tem com o alimento que comercializa e com o seu freguês. Os feirantes orgânicos são apenas produtores e demonstraram cuidado com o alimento e com as pessoas que buscam o seu produto, diferentemente dos feirantes convencionais que tratam o alimento como mercadoria. Para os feirantes ecológicos seus fregueses buscam este alimento porque se preocupam com a sua saúde e com o meio ambiente, percepção distinta dos feirantes convencionais que tem um padrão de alimentos que são comercializados, e que apontam que as pessoas buscam o alimento pela estética e não pela saudabilidade. É preciso relativizar os fatores que podem estar imbricados no valor agregado aos alimentos comercializados nas feiras, assim como na produção e na escolha de alimentos que são socialmente e culturalmente concebidos como saudáveis e que promovem a saúde e a segurança alimentar e nutricional.
\end{abstract}

Palavras chaves: feiras-livres; alimentação; segurança alimentar e nutricional; desenvolvimento regional

\section{The value of fruits and vegetables sold in open markets and their interface with Food and Nutrition Security (FNS)}

Abstract

The present study aimed to promote reflection on the valuation of food that fair workers produce and / or sell, and, moreover, how this process relates to the food and nutritional security of all actors involved in the food system. It is a qualitative research, with ethnographic inspiration. In data collection, in-depth interviews and participant observation were carried out at organic and conventional fairs, in addition to organic production sites, during the years 2013 and 2014 in the municipality of Pelotas/RS and region. As main results it was obtained that there are in the fairs have who only producers, those who produce and resell, and only that resellers, this fact influences the relationship that the fair workers have with the food he sells and with his customer. Organic fair workers are only producers and have shown care with food and with people who seek their product, unlike conventional fair workers who treat food as a commodity. For ecological fair workers, their customers look for this food because they care about their health and the environment, a different perception from conventional fair workers who have a pattern of foods that are marketed, and that point out that people look for food by aesthetics and not for healthiness. It is necessary to put into perspective the factors that maybe intertwined in the added value the foods sold at fairs, as well as in the production and choice of foods that are socially and culturally conceived as healthy and that promote health and food and nutritional security.

Keywords: street markets; food; food and nutrition security, regional development.

${ }^{1}$ Doutoranda no Programa de Pós-Graduação em Enfermagem na Universidade Federal de Pelotas (UFPel).

Nutricionista na área de Saúde Pública e Segurança Alimentar e Nutricional. http://orcid.org/0000-0001-8593-1397 E-mail: mila85@gmail.com

2 Doutorado em Antropologia (UFPE). http://orcid.org/0000-0002-9886-4362 E-mail: evanderkrone@gmail.com

${ }^{3}$ Doutorado em Antropologia Social. Professora da Universidade Federal de Pelotas (UFPel).

http://orcid.org/0000-0002-8707-6037 E-mail: renata.menasche@gmail.com 


\section{Introdução}

O conceito contemporâneo de Segurança Alimentar e Nutricional (SAN) foi construído a partir do aporte de movimentos sociais e de Governos no decorrer do processo de apreensão da noção de SAN no Brasil (MALUF,2009). Neste sentido, o Estado incorporou e legitimou através da Lei Orgânica de Segurança Alimentar e Nutricional, o conceito aprovado em 2004 na II Conferência Nacional de SAN reconhecendo para tanto que para alcançar a SAN não basta apenas ter acesso a um conjunto de alimentos que satisfaça as necessidades fisiológicas dos sujeitos, uma vez que os alimentos devem ser de qualidade (social, ambiental e econômica), promover a saúde e estar de acordo com a cultura alimentar dos grupos humanos (BRASIL,2006).

Os principais tratados, definições e conceptualizações em torno da SAN têm convergido para o entendimento de que a alimentação é um direito humano e uma obrigação do Estado em prover o seu acesso por meio de políticas que respeitem os princípios dos direitos humanos tais como igualdade, dignidade, liberdade, entre outros, associados ainda à soberania alimentar das populações ao definirem os aspectos relativos às suas escolhas alimentares e hábitos culturais.

Ainda que o ato de comer seja uma atitude corriqueira do nosso dia a dia, esta ação traz consigo consequências que podem ser irreversíveis para o corpo. Do ponto de vista biológico, o alimento ingerido é absorvido pelo corpo, as suas propriedades bioquímicas podem gerar a energia, o combustível que torna possível a continuidade da vida ou mesmo podem levar a morte quando o alimento comido estiver contaminado. Segundo Fischler (2001), o ato fundamental que evidencia a angústia do comensal é a incorporação, o momento pelo qual o alimento atravessa a fronteira entre o mundo e o nosso corpo. Medos, anseios, mitos e fantasmas concorrem na regulação diária dos nossos hábitos alimentares (MACIEL; CASTRO,2013).

Por isso, incorporar um alimento e torná-lo parte do nosso corpo é um ato tanto real como imaginário, pois a alimentação humana implica em valoração simbólica. Comer é uma necessidade básica de todo ser humano, porém o consumo alimentar é regulado em função de classificações morais, políticas, econômicas e religiosas. Assim, comer supõe não apenas incorporar as características bioquímicas dos alimentos, mas envolve também a absorção das qualidades morais atribuídas aos alimentos, sejam elas positivas ou negativas. O que se come, como e com quem se come são práticas aprendidas durante o transcorrer da vida de cada um, sendo influenciadas por signos culturais e sociais historicamente determinados, uma vez que como observado por Mintz (2001; p. 31) "o comportamento relativo à comida liga-se diretamente ao sentido de nós mesmos e à nossa identidade cultural". 
Portanto, a prática alimentar deve ser compreendida no universo de representações em que os alimentos estão inseridos, já que são apreendidas no meio em que a pessoa nasceu, cresceu e foi educada (DANIEL; CRAVO,2005). As autoras Amon e Menasche (2008) expressam essa questão por meio da narrativa de duas receitas de comidas cotidianas de uma família judia sefardi radicada no Brasil. Por meio desse artigo, as autoras buscam resgatar a memória cultural do lugar de onde vêm tais receitas, evidenciando os significados simbólicos, culturais e emocionais que estão associados aos ingredientes e a um modo de preparo tão habitual e, ao mesmo tempo, tão singular (AMON; MENASCHE, 2008).

Nesse sentido, a alimentação humana reflete uma forma de conceber o mundo e, portanto, os alimentos são detentores de funções sociais, eles identificam e diferenciam, marcam e delimitam fronteiras entre diferentes grupos sociais, gerando, assim, identidades alimentares próprias. É o caso do arroz dos chineses, do macarrão e da pizza dos italianos e da feijoada dos brasileiros (MINTZ,2001).

Com o advento do capitalismo e o aprofundamento do fenômeno da globalização, a identidade alimentar sofre fortes impactos. A padronização da alimentação leva a mudanças nos hábitos alimentares culturalmente estabelecidos, em um contexto de industrialização da comida. A partir do século XX grande parte dos saberes e práticas associadas aos processos de elaboração e transformação dos alimentos foram descoladas do ambiente familiar para a indústria. A industrialização promoveu, em grande medida, uma desnaturalização e dessocialização dos alimentos, deslocando-os do seu ambiente natural e do universo social onde eram tradicionalmente produzidos, comercializados e consumidos, para um ambiente fabril, não familiar e distante dos olhos do consumidor.

Como mostram Contreras e Gracia (2011), o atual estágio do comércio de alimentos, estreitamente ligado a um processo mais amplo de globalização, promoveu a deslocalização da produção de alimentos. Não há mais necessidade de que aquilo que uma determinada população consome seja produzido perto do local de consumo. Desta forma, a indústria agroalimentar influenciada pelos movimentos mais gerais da globalização promoveu um rompimento entre os alimentos e o seu universo social de produção.

Esse processo faz com que muitos consumidores reconheçam apenas os elementos terminais presentes nas prateleiras dos supermercados e redes de distribuição, enquanto o restante do complexo sistema agroalimentar é uma verdadeira "caixa-preta" (CONTRERAS; GRACIA,2011). No mundo urbano-industrial do século XXI plantar e colher o que será consumido é um hábito que não se faz mais presente na vida da maior parte da população. Deste modo, a 
comida vem e vai com uma velocidade e um volume que ocultam os processos de produção e consumo (MINTZ,2001), logo os alimentos, de forma geral, tornaram-se meras mercadorias. O modelo de produção do sistema capitalista retira a comida do seu universo social de produção, promovendo uma ruptura entre produtores e consumidores e enfraquecendo as habilidades culinárias, posto que possibilita o acesso a alimentos produzidos para o consumo imediato.

Nesse sentido, entende-se que a revalorização das comidas cotidianas - especialmente as frutas, legumes e verduras (FLV), pode contribuir na promoção da SAN e da saúde de produtores e consumidores (DANIEL; CRAVO,2005). A busca pela reaproximação entre esses atores, associada à redescoberta do sistema alimentar, compreendido, aqui, conforme descrevem os autores Poulain e Proença (2003; p.252), como "conjunto de estruturas tecnológicas e sociais empregadas desde a coleta até a preparação culinária, passando por todas as etapas de produção e transformação", são caminhos necessários a se percorrer na busca da SAN e da saúde da população.

Diante do exposto, o presente estudo busca refletir, sob a perspectiva dos feirantes, como ocorre e é valorada a produção e comercialização de FLV no espaço das feiras livres. Busca-se, ainda, pensar como o processo de produção das FLV e seu comércio em feiras se relacionam com a SAN e com a saúde de produtores, comerciantes e consumidores.

\section{Metodologia de pesquisa}

A inserção em campo e a coleta de dados realizada no transcorrer deste estudo ocorreram durante o período de dezembro de 2013 a agosto de 2014, tendo como recorte empírico da pesquisa os municípios gaúchos de Pelotas, Morro Redondo e Turuçu. Os locais pesquisados foram feiras convencionais e orgânicas, locais de produção de FLV orgânicos, e um estabelecimento comercial de varejo de FLV.

Cabe ressaltar que no município de Pelotas existem dois tipos de feiras que são nomeadas (pelos feirantes e pela gestão municipal) de acordo com o modo como é realizada a produção de alimentos. Nas feiras convencionais, os alimentos são comercializados, em parte, por agricultores familiares. No entanto, em alguns casos, as FLV são revendidas por feirantes que não se enquadram na categoria de produtores. Os feirantes revendedores compram esses alimentos de agricultores familiares da região ou na Associação de Comerciantes de Hortifrutigranjeiros de Pelotas. Neste local são comercializadas FLV que são produzidas em todo o país, como mamão, 
manga, cebola e batata. Os alimentos vendidos nas feiras convencionais são produzidos sem restrição à utilização de insumos.

No caso das feiras orgânicas, há somente produtores ecológicos, que comercializam alimentos produzidos sem utilização de agroquímicos e com base em princípios da produção ecológica, ou seja, busca-se harmonizar a produção agrícola de acordo com as condições climáticas, o tipo de solo e seus nutrientes. Desse modo, nessas feiras são encontradas FLV da época, estação do ano. Portanto, existem três tipos de feirantes: os que são somente produtores, aqueles que são produtores e revendedores, e os que são exclusivamente revendedores. Os produtores das feiras ecológicas denominam-nas como orgânicas, por isso serão utilizadas as duas denominações como sinônimas.

Para a coleta dos dados, tomaram-se como ponto de partida inserções em feiras dos dois tipos. Tais entradas a campo ocorreram no mesmo período, mas de modos distintos. Utilizou-se, no transcorrer do estudo, a inspiração no método etnográfico, sendo realizadas entrevistas em profundidade e observação participante, com registro em diário de campo. Partindo da ideia do contato como fundadora da relação etnográfica entre interlocutor e pesquisador, buscou-se construir uma interação prolongada com os sujeitos estudados de modo a penetrar em suas formas de viver e de pensar. Nestes termos a pesquisa foi baseada em uma "descrição densa" em que o trabalho interpretativo de ler e interpretar o discurso social for realizado a partir de uma aproximação do ponto de vista nativo (GEERTZ,2008).

Já no que diz respeito ao conceito de observação participante, tal qual formulada pelos autores Schwartz \& Schwartz (1955) apud Minayo (2014; p. 273), é possível defini-la como: “um processo pela qual mantém-se a presença do observador numa situação social, com a finalidade de realizar uma investigação científica". Desse modo, o pesquisador encontra-se frente a frente com os sujeitos observados. A coleta dos dados, por consequência, se dá no espaço onde atuam, de modo a manter uma interação constante com suas práticas socioculturais.

Na presente pesquisa, foram realizadas diferentes observações: a observação dirigida, com o objetivo de complementar as informações obtidas nas entrevistas (sendo desempenhado o papel de observador-como-participante); e a observação livre e descritiva, por meio da qual se tornou claro para os envolvidos que o tempo de pesquisa determinaria a relação no campo (sendo desempenhado o papel de participante-como-observador). Seguindo esta última forma de observação, foram adotados hábitos, formas de atuação e acompanhamento de acontecimentos importantes para os entrevistados em suas rotinas (MINAYO,2014; CICOUREL,1980). As informações obtidas na convivência com os atores sociais estudados foram 
registradas com o auxílio do diário de campo. Desse modo, os registros e impressões do diário de campo foram sistematizados procurando permitir a análise do comportamento das pessoas com o ambiente, entre elas mesmas e com a pesquisadora (Victora; Knauth; Hassem,2000).

Nesse sentido, optou-se por realizar as entrevistas nos próprios locais de feira. Seguindo a linha de estudo proposta, foram utilizadas questões norteadoras, uma vez que elas ajudam a guiar a conversa, estimulando os interlocutores a falarem livremente sobre os aspectos que consideravam importantes no que diz respeito à produção e à comercialização de FLV. Nas feiras convencionais, algumas entrevistas foram agendadas e outras ocorreram espontaneamente. $\mathrm{Na}$ feira ecológica, as entrevistas ocorreram sem agendamento e obedeceram à disponibilidade dos feirantes durante o período de realização do trabalho de campo.

A inserção em campo deu-se, por conseguinte, a partir de estratégias distintas nos diferentes tipos de feiras. Nas feiras de tipo ecológico, foram duas etapas sucessivas: exploratória e de imersão. Nas feiras de tipo convencional, dada a limitação temporal da pesquisa, realizada durante o primeiro ano do mestrado da pesquisadora, utilizou-se da aproximação decorrente da aplicação dos questionários para a coleta dos dados quantitativos (o estudo teve uma etapa com abordagem quantitativa). Dessa forma, por conveniência e vínculo gerado pela etapa quantitativa, foram eleitos os interlocutores a serem entrevistados posteriormente.

Nas feiras ecológicas, a imersão a campo foi precedida por dois momentos de pesquisa exploratória. Na fase exploratória, buscou-se conhecer o ambiente de pesquisa e estabelecer os primeiros contatos com os feirantes e, com isso, possibilitar a entrada em campo. $\mathrm{O}$ primeiro momento ocorreu na feira ecológica que se realiza às quintas-feiras no centro da cidade de Pelotas, no Largo do Mercado Municipal. Nessa etapa, não se obteve sucesso, já que, devido ao grande movimento de consumidores e à falta de conhecimento prévio dos feirantes, a abertura para futura inserção de pesquisa não chegou a realizar-se.

Diante do ocorrido, procurou-se estabelecer um elo com os feirantes, cuja realização apenas se tornou possível a partir da colaboração de uma graduanda do curso de Gastronomia da UFPel, por intermédio do Grupo de Estudos e Pesquisas em Alimentação e Cultura - GEPAC, coordenado por uma das coorientadoras da presente pesquisa, a professora Renata Menasche. Habituada ao meio rural, moradora da colônia Coxilha dos Campos, em Canguçu, a estudante oportunizou a aproximação com Onofre, produtor e feirante ecológico, morador da Coxilha dos Silveiras.

No início do mês de dezembro de 2013, na feira ecológica que se realiza aos sábados, na Avenida Dom Joaquim em Pelotas, a graduanda intermediou a primeira conversa com Onofre. 
Após explicar os objetivos da presente pesquisa ao feirante - e vendo que ele se mostrava receptivo ao estudo -, houve sua aceitação em participar da pesquisa, explicando o funcionamento da feira e de sua produção. É importante ressaltar que a oportunidade para a realização da observação participante se deu a partir da mediação de pessoa conhecida e de confiança do feirante, dado que a graduanda e a família a que pertence fazem parte da rede de sociabilidade de Onofre. Na comunidade rural, a forma como as pessoas pertencentes a esse grupo se organizam leva à promoção de relações solidárias e de pertencimento cuja lógica está imbricada na vivência desses sujeitos, sobrepondo-se a situações determinadas a partir de "parentesco, vizinhança, cooperação no trabalho e coparticipação nas atividades lúdicoreligiosas" (COMERFORD; 2005, p. 112). Confirma-se, assim, o que afirma Minayo (2014; 282283): "certamente as pessoas que introduzem o pesquisador no campo são com ele responsáveis tanto pela sua primeira imagem, como por portas que se abrirão ou se fecharão".

A inserção a campo, nesta feira, marca o início da segunda etapa da pesquisa, com a observação participante, que ocorreu aos sábados do período compreendido entre dezembro de 2013 e maio de 2014. Durante esse período, a pesquisadora participou das atividades de venda dos produtos na banca de Onofre. Foi um período de importante interação junto aos feirantes, com trocas interpessoais e experiências que possibilitaram de forma mais ampla a apreensão do contexto vivenciado pelos feirantes. Na banca de Onofre, a pesquisadora, em observação participante, assumiu tarefas que lhe foram determinadas e foi orientada pelo feirante a respeito da postura a ser adotada no trato com os fregueses.

Durante o período de vivência na feira ecológica da Avenida Dom Joaquim, foram realizadas entrevistas com um feirante de cada banca, totalizando sete entrevistas. Além disso, foi possível conhecer as propriedades rurais de Onofre e do casal Isabel e Alceu. A visita à propriedade de Onofre, no município de Canguçu, vizinho a Pelotas, ocorreu em março de 2014. E, em maio de 2014, houve a oportunidade de conhecer a propriedade rural de Isabel e Alceu, localizada no interior do município de Turuçu, próximo a Pelotas.

Nesta pesquisa todos os preceitos éticos forma respeitados, sendo assim, a participação dos feirantes, foi voluntária e a realização da entrevista ocorreu somente após o entendimento e a assinatura do Termo de Consentimento Livre e Esclarecido. O presente estudo foi aprovado pelo Comitê de Ética em Pesquisa da Faculdade de Medicina/UFPel, com o número do parecer 532.894. Para preservar a identidade dos interlocutores, os nomes utilizados neste artigo são fictícios. 
No transcorrer deste estudo, foram entrevistados sete feirantes/produtores ecológicos e sete feirantes convencionais. Dentre os feirantes convencionais entrevistados, quatro são homens e três são mulheres, com idades entre 30 e 60 anos, em sua grande maioria casados e com escolaridade variando de 4a série do ensino fundamental a ensino médio completo. Cinco feirantes convencionais eram apenas revendedores, os demais também produziam para vender. A maior parte destes comerciantes residia na zona urbana e exercia a profissão há mais de dez anos.

Com relação aos feirantes ecológicos, a idade variou de 34 a 68 anos, todos eram casados, cinco são do sexo masculino. A escolaridade é semelhante à dos feirantes convencionais, assim como o tempo de profissão. O perfil torna-se diferenciado no que tange à localidade de moradia e em relação ao alimento, uma vez que todos os feirantes ecológicos residem na zona rural e comercializam apenas os alimentos que produzem, não comprando de outros produtores para revender nas feiras.

\section{Produzir, comprar e vender: as relações estabelecidas por feirantes com os alimentos e com os consumidores}

Tanto os produtores (orgânicos e convencionais) como os revendedores demonstraram conhecimento sobre a produção dos alimentos. A partir dessa compreensão surgem diferentes relações com os alimentos e com os fregueses das feiras.

Para os feirantes orgânicos, pode-se sugerir que o alimento tem relação com a imagem que esses sujeitos fazem de si próprios. Isso se expressa no processo de partilha estabelecido junto ao freguês, em que os produtores buscam enfatizar as qualidades diferenciadas da sua produção, evidenciado a existência de uma relação moral com a produção de comida. Como demonstrado pelo estudo de E. Woortmann (1995) com sitiantes nordestinos, para os agricultores familiares a produção agrícola possui, além de significado econômico um significado ético, uma vez que a própria condição de agricultor se expressa na produção de alimentos (WOORTMANN;1995). Fato que o Sr. Nicolas busca enfatizar:

O que vale é a forma de tratar o alimento. Produzir com carinho o alimento que vai alimentar o teu parceiro, o teu consumidor, o nosso freguês aqui. Ele não é só nosso freguês. Ele é nosso amigo, é uma pessoa que te conhece por nome, conhece a nossa propriedade, isso que é o mais interessante. Ele chega aqui e pergunta como está a lavoura de brócolis, se aquele pêssego produziu bem. Tudo isso eles estão sabendo. Então é uma troca. Isso é gratificante. 
De acordo com os produtores orgânicos os fregueses demandam por esse tipo de alimento pensando em manter uma alimentação saudável. Desse modo, segundo os interlocutores entrevistados, os consumidores sentem a diferença no gosto do alimento e sabem identificar de onde vem o produto. Tais consumidores, por consequência, buscam uma produção limpa, principalmente no que tange à utilização de insumos químicos como mostram os relatos de dois feirantes, reproduzidos abaixo:

\footnotetext{
O pessoal que compra aqui vê a diferença. Tem muitos que dizem: "ah, isso é bobagem". Mas tem uns que já estão acostumados. Há anos vêm aqui. Eles veem a diferença do produto também no gosto. (Alceu)

O produto que é produzido dentro das propriedades orgânicas é um produto que tem rosto! Então, se chegar no consumidor ou no mercado, tu vais saber onde e como ele foi produzido. Agora, se tu pegar um produto do CEASA, convencional, esse produto é só um produto, pois não dá para saber como ele foi produzido. (Nicolas)
}

A conversão à produção de alimentos orgânicos foi semelhante para os produtores entrevistados, que, em algum momento de suas vidas, já haviam trabalhado com produção convencional ou com a fumicultura que é uma atividade extremamente dependente do uso de agrotóxicos. Nesse sentido, as intoxicações e hospitalizações provocadas por conta da utilização de agrotóxicos motivaram os produtores a repensar a maneira de produzir. Os produtores relataram que não gostavam de trabalhar com o fumo e que as verduras produzidas passavam por atravessadores antes de serem comercializadas. Alguns disseram que, se tivessem que voltar a lidar com veneno deixariam a profissão.

$\mathrm{Na}$ contramão desse sentimento negativo gerado pela produção convencional, a produção ecológica é referida como algo feito com amor e carinho, capaz de mudar a maneira de ver e viver a vida. Nicolas conta, por exemplo, que quando iniciou a produção ecológica de alimentos, passou a dar valor para as pequenas coisas. Além disso, o agricultor relatou que sua maneira de pensar o ambiente também mudou, uma vez que o alimento começou a ser visto como um ser vivo, que precisa de contato diário e direto. Antes, Nicolas estava acostumado e focado na produção agrícola em função de uma racionalidade econômica e instrumental, porém na atualidade, ele revela ter o entendimento de que na produção orgânica de alimentos "há que se proteger e trabalhar junto com a natureza, e não se apropriando dela".

Para se adequar a esse novo modo de plantar e viver, os agricultores e suas famílias precisaram aprender a trabalhar de acordo com as características de cada propriedade, com o clima e com a natureza. A terra e as pessoas não estavam preparadas. Na produção convencional de alimentos ou no fumo, que antes ali eram cultivados, utilizavam-se insumos químicos. Foi 
necessário preparar-se para colher, inicialmente, a metade da produção. Além disso, não havia, à época em que começaram a plantação de orgânicos, exemplo desse tipo de produção na região.

De acordo com Gustavo o trabalho no cultivo de orgânicos não é fácil, já que a quantidade produzida não é a mesma que nos cultivos convencionais. O agricultor passa, então mais tempo na lavoura, capinando, tirando a sujeira, conforme relata Gustavo:

\begin{abstract}
Com veneno vai dar um produto mais graúdo, vai produzir mais. O nosso é um pouco mais caro. A gente vê isso aí, mas a gente não produz com veneno. Cenoura é três reais o molho, mas, para limpar uma área pequena, duas pessoas levam 14 dias, batendo dia por dia, arrancando a sujeira, chega a sangrar os dedos. Com veneno, 20 lavouras pequenas, em uma hora, fica tudo limpo. É só pegar a máquina, colocar o herbicida e não precisa olhar mais. Dá aquela cenoura lisinha, bonitinha, cheia de veneno.
\end{abstract}

Diante das relações que se estabelecem em torno da produção e comercialização das FLV, entende-se que é preciso refletir para além da função biológica do alimento. Deve-se considerar, por conseguinte, os aspectos sociais e culturais que lhes são inerentes, e que fazem parte da promoção da SAN. As autoras Maciel e Castro (2013) argumentam que as comidas, constituídas de seus "nutrientes e simbolismos", possuem valor para além do aspecto nutricional, pois contribuem para que a sociedade reflita sobre a realidade que a circunda.

Os seres humanos têm a necessidade constante de identificar e classificar os alimentos, tanto do ponto de vista biológico como simbólico, criando prescrições e proscrições alimentares. As sociedades humanas criaram regras, práticas, classificações e hierarquias que regulam o ato alimentar. Nesse sentido, o próprio gosto e as práticas alimentares são socialmente ensinados e instituídos. Portanto, a cultura influencia no que é considerado adequado para se comer. Desse modo nem tudo que é comestível na natureza é considerado comestível do ponto de vista cultural (FISCHLER,2001). Considerando-se o simbolismo constitutivo dos alimentos vendidos nas feiras ecológicas, pode-se pensar, a priori, que seus frequentadores terão os seus comportamentos alimentares influenciados e, até mesmo, modificados pelas trocas de saberes que ali ocorrem.

No entanto, não se pode deixar de levar em consideração que o produtor constrói, por meio da relação com o consumidor e com o alimento, a ideia de que comercializa uma mercadoria diferenciada, uma vez que pretende vender os seus produtos, os quais fundamentam sua fonte de renda e sustento familiar.

As relações estabelecidas entre feirantes e fregueses - e os valores atribuídos às FLV por ambos - podem ser consideradas como um impulso de mudança frente à modernidade 
alimentar, marcada pela praticidade e pelo alto consumo de alimentos ultra processados, sem identidade local, pois o cuidado que os produtores ecológicos demonstram para com o alimento, os fregueses e eles mesmos pode modificar a relação dominante de consumo de alimentos prontos, não saudáveis do ponto de vista da promoção da saúde e da SAN. Observa-se, com isso, que, por meio do diálogo que o produtor propõe, pode haver uma mudança nos hábitos e valores que sustentam as práticas e relações com o alimento.

Os consumidores que frequentam essas feiras, por sua vez, incentivam esse tipo de produção. Esses comensais não consideram apenas as suas escolhas individuais, ligam-se a um ambiente com aspectos sociais e culturais que os permitem pensar e acompanhar o alimento em todo o seu processo, avaliando a sua produção e os seus impactos coletivos. Tais "tribos alimentares", utilizando-se do conceito de Lifschitz (1997), consideram as FLV como alimentos naturais, uma vez que provêm da terra, da natureza, "e se originam de misturas manuais, do contato com a matéria-prima com o calor e a pressão das mãos" (p. 72). Para essas pessoas, quanto mais distante o alimento está da terra e do produtor, menos natural ele é considerado.

Nas feiras convencionais, a maioria dos revendedores relatou conhecer os produtores que Ihes fornecem as FLV e como eles tratam os alimentos, mas, para esses comerciantes, as FLV são percebidas, primordialmente, como mercadoria. Essa relação pode ser explicada porque este tipo de feirante não mantém uma relação direta, de cuidado, com a produção, e, também, pela influência do modelo econômico na relação com o alimento. Conforme os salientam Daniel e Cravo (2005; p.61), “(...) nesse contexto o alimento é mercadoria, e só pode ser obtido por outra mercadoria: o dinheiro".

Os produtores convencionais preocupam-se com relação à utilização do agrotóxico. Eles sabem do perigo e dos malefícios que este insumo ocasiona para a saúde, mas, por considerarem que a produção ecológica rende pouco e, por assim terem aprendido o ofício de produtor, continuam a utilizar o veneno. Conforme as palavras de Everaldo (feirante e produtor convencional), se conseguir, com um veneno mais fraco, evitar que o bicho entre no alimento, é melhor, porque quando a praga contamina a planta, é preciso usar um veneno mais forte. Ele explicou que o remédio (veneno) é muito caro e demonstrou preocupação com o tema. De acordo com a sua experiência, caso o agricultor fique na dependência deste produto (veneno), não ganha nem para pagar o veneno. Assim, pode-se inferir que, por questões sociais e culturais, os feirantes convencionais, que muitas vezes são também consumidores de suas FLV, sabem dos perigos que os agrotóxicos ocasionam e, talvez não de forma consciente, assumem o risco de usar uma tecnologia perigosa (os agrotóxicos), pois ela traz vantagens econômicas. 
Com relação aos valores que os consumidores atribuem às FLV - e que levam em consideração na hora de comprar os alimentos -, os feirantes alegaram que os fregueses requerem alimentos de boa aparência, bonitos, havendo pouca preocupação com os meios utilizados para que se atinja esse patamar. Alguns feirantes comentaram que explicam aos clientes as diferenças entre os alimentos produzidos com mais ou menos insumos químicos, mas, na maioria das vezes, é a apresentação exterior que faz com que o produto seja vendido, como evidenciado pelas falas reproduzidas abaixo de dois feirantes convencionais

\footnotetext{
Para o tomate gaúcho ficar grandão e bonito leva muito veneno. Vai um tratamento. Eu tento não pegar aquele que é bonito porque eu sei que aquilo ali está contaminado. Eu pego o mais feio. Aí as pessoas falam: "ah, tá feio". Está feio, mas é esse que tu tens que comer. Não o bonito! Mas tem muita gente que não entende. Muito é pelo olho, né? Se tem uma mercadoria bonita, os fregueses levam, mas eles não sabem o que estão levando, o que estão consumindo. (Valter)

Os clientes perguntam sobre agrotóxico e essas coisas, mas a gente tenta explicar isso aí. Se não colocar nada, não vais ter um produto com qualidade. Vais ter um produto mais puro, mas com uma aparência inferior. Hoje em dia é a aparência que manda no produto. (Reinaldo)
}

Conforme relata Elizabete (feirante revendedora) em sua banca há um padrão de alimentos comercializados. A época e o preço não influenciam. O que importa é a mercadoria procurada pelo freguês. Por conseguinte, pode-se pensar o consumo a partir da conjunção de dois fatores capazes de influenciar o feirante na compra e na venda de FLV, são eles:

A função simbólica do alimento: os produtos vendidos nos espaços de feiras remetem a significados específicos, uma vez que esses locais reportam ao ambiente rural, o qual tem sido romantizado e idealizado por habitantes dos centros urbanos. O rural, portanto, aparece no imaginário urbano relacionado à liberdade, à natureza, à saúde, logo os alimentos que vêm da terra são associados à ideia de alimentos mais naturais (CRISTÓVÃO,2002). Em publicação onde foi abordada a percepção de agricultores e moradores da cidade de Porto Alegre sobre o tema da ruralidade, Menasche (2010) relata que os citadinos consideram que "de fora são os alimentos que vêm do interior, do meio rural, cuja origem é associada diretamente ao produtor" (p.8). Nesse sentido é possível compreender que as FLV comercializadas nas feiras carregam a imagem de alimento "natural", uma vez que os consumidores acreditam que os alimentos vendidos nestes locais são mais frescos e bonitos e os aproximam dos produtores.

A alimentação moderna: as mudanças nos estilos de vida provocadas pela globalização influenciaram as práticas alimentares. Segundo Contreras (2005), a alimentação sofreu uma 
homogeneização; modificaram-se os comportamentos alimentares: o que, como e com quem comer. Além disso, segundo Fischler (2001), no alimento moderno não há mais uma identidade. Isso pode ser explicado pelas mudanças que ocorreram - e continuam a ocorrer - no sistema alimentar, o qual agregou, principalmente nas últimas décadas, a industrialização do sistema agrícola, a produção em grande escala e a concentração de multinacionais. Na alimentação moderna, há cada vez mais um distanciamento entre o produtor e o consumidor. Processo que também ocorre, em parte, nas feiras, quando se pensa nos alimentos que são revendidos. De acordo com Fischler (2001), a incerteza sobre quais alimentos se devem consumir é responsável pela angústia do comensal moderno.

Todos esses fatores podem estar levando o feirante e o consumidor a ignorar - até mesmo de maneira inconsciente - o modo como as FLV que revendem e consomem são produzidas e comercializadas. Dessa forma, estes sujeitos parecem não dar muita atenção para os aspectos coletivos envolvidos nessa questão, mas sim para as suas necessidades individuais. Trata-se, aqui, da questão financeira, de sustento do feirante e do ato de consumir um alimento considerado saudável pelo freguês, que pode fazer bem à sua saúde. Diante disso, salienta-se que estes atores estão inseridos em uma sociedade com hábitos e comportamentos sociais, econômicos e culturais, os quais são responsáveis por impulsioná-los a tomar tal atitude, estabelecendo uma forma particular de se relacionar com o alimento.

As FLV são conceituadas pela sociedade (órgãos e profissionais da saúde, mídia, consumidores) como "alimentos de qualidade", no entanto, ao considerar essa atribuição, os feirantes convencionais e os fregueses dessas feiras parecem não considerar a maneira como ocorre sua produção, comércio e as relações socioeconômicas que se desencadeiam a partir dessa primeira etapa. Isso porque eles também consideram as FLV como alimentos naturais, mas, diferentemente da forma como ocorre com as "tribos alimentares", tal definição é impulsionada pelas recomendações dos profissionais da saúde, da indústria e da mídia ${ }^{16}$. Novamente, toma-se Lifschitz (1997) como referência, pois é preciso descrever o que é considerado natural para os referidos grupos. Segundo esse autor, "o natural se insere no discurso do saber legitimado sobre a 'boa alimentação', isto é, sobre a adequação entre propriedades físico-química dos alimentos e normas que obedecem a um padrão fisiológico e anatômico" (LIFSCHITZ; 1997, p. 72). Essa afirmação remete às normas estipuladas pelos profissionais da área da saúde ao recomendarem o que deve ou não ser consumido.

Mas a questão envolve ainda "o natural" enquanto peça publicitária. A autora Wille 20 chama a atenção para o fato de que já é habitual a apropriação dos "atributos artesanal, caseiro 
e natural" pelas indústrias alimentícias em suas embalagens e propagandas. Ao analisar uma embalagem de extrato de tomate, Wille (2014) refere que, "ao centro, há a imagem de tomates molhados e, convém salientar, esteticamente perfeitos, que dão a ideia de produtos frescos, recém-colhidos, o que é reforçado pelo cesto de vime, que também sugere um ambiente rústico e caseiro" (p. 85).

Os distintos aspectos que influenciam no valor que os feirantes das feiras orgânicas e convencionais atribuem aos alimentos, estão diretamente relacionados aos impactos na saúde deles e de seus consumidores, assim como na Segurança alimentar e Nutricional, cabe lembrar que tal conceito abrange questões sociais, simbólicas, econômicas e culturais que perpassam todo o sistema alimentar, da produção ao consumo.

\section{Considerações finais}

O presente estudo atingiu o objetivo proposto ao expor e problematizar os fatores que influenciam na valoração da produção e comercialização de FLV no espaço das feiras livres orgânicas e convencionais. Os temas levantados podem contribuir para (re) pensar as práticas e orientações alimentares, pois demonstram a complexidade que envolve a produção, comercialização e escolha de alimentos - frutas, legumes e verduras - que são socialmente e culturalmente concebidos como saudáveis e que promovem a saúde e a SAN. Torna-se necessário expandir os estudos que permitam conhecer e discutir as relações com os alimentos, dentro da amplitude de atores e elementos do sistema alimentar.

\section{Referências}

AMON, Denise; MENASCHE, Renata. Comida como Narrativa da Memória Social. Sociedade e Cultura, v.11, n.1, p. $13-21,2008$. Disponível em: https://www.revistas.ufg.br/fcs//article/view/4467. Acesso em: 15 mar. 2019

BRASIL. Lei $n \cong 11.346$, de 15 de setembro de 2006. Cria o Sistema Nacional de Segurança Alimentar e Nutricional (SISAN) com vistas em assegurar o direito Humano à alimentação adequada e dá outras providências. Diário Oficial [da] República Federativa do Brasil, Brasília, DF, 15 set. 2006.

CICOUREL, Aaron. Teoria e método em pesquisa de campo. In: GUIMARÃES, Alba Zaluar. Desvendando máscaras sociais . Rio de Janeiro: Francisco Alves, 1980.

COMERFORD, John Cunha. Comunidade Rural. In: Motta, Márcia (Org.). Dicionário da Terra. Rio de Janeiro: Civilização Brasileira, 2005. 
CONTRERAS, Jesus. Patrimônio e Globalização: o caso das culturas alimentares. In: CANESQUI, Ana Maria; GARCIA, Rosa Wanda Diez. Antropologia e nutrição: um diálogo possível. Rio de Janeiro: Fiocruz; 2005.

CONTRERAS, Jesus; GRACIA, Mabel. Alimentação, sociedade e cultura. Rio de janeiro: Fiocruz; 2011.

CRISTÓVÃO, Artur. Mundo Rural: Entre as representações (dos urbanos) e os benefícios reais (para os rurais). In: RIEDL, Mario; ALMEIDA, Joaquim A.; VIANA, Andyara L. B.. Turismo rural: Tendências e sustentabilidade. Santa Cruz do Sul: EDUNISC; 2002.

DANIEL, Jungla Maria Pimentel; CRAVO, Veraluz Zicarelli. Valor Social e Cultural da Alimentação. In: CANESQUI, Ana Maria; GARCIA, Rosa Wanda Diez. Antropologia e nutrição: um diálogo possível. Rio de Janeiro: Fiocruz; 2005.

FISCHLER, Claude. L'homnivore. Paris: Poche Odile Jacob ; 2001.

GEERTZ, Clifford. A interpretação das Culturas. 1a ed. 13ำ reimp. Rio de Janeiro: LTC; 2008.

LIFSCHITZ, Javier. Alimentação e cultura: em torno ao natural. Revista Physis, v.7, n.2, p. 69-83, 1997. Disponível em: https://scielosp.org/article/physis/1997.v7n2/69-83/pt/. Acesso em: 10 fev. 2019

MACIEL, Maria Eunice; CASTRO, Helisa Canfield de. A comida boa para pensar: sobre práticas, gostos e sistemas alimentares a partir de um olhar socioantropológico. Demetra, v. 8, Supl.1, p. 321-28, 2013. Disponível em:

https://pdfs.semanticscholar.org/d3fb/4c417092638e3342297d85f801ac1c6d5af9.pdf. Acesso em: 10 fev. 2019

MALUF, Renato. Segurança alimentar e nutricional. Petrópolis - Rio de janeiro : Vozes; 2009.

MENASCHE, Renata. Campo e cidade, comida e imaginário: percepções do rural à mesa.

Ruris, .v 3, n.2, 195-218, 2010. Disponível em:

https://www.ifch.unicamp.br/ojs/index.php/ruris/article/view/700. Acesso em: 10 fev. 2019

MINAYO, Maria Cecília de Souza. O Desafio do Conhecimento: Pesquisa Qualitativa em Saúde. São Paulo: Hucitec, 2014.

MINTZ, Sidney. Comida e Antropologia: Uma breve revisão. RBCS, v. 16, n.47, p. 31-41, 2001. Disponível em: https://www.scielo.br/pdf/rbcsoc/v16n47/7718.pdf. Acesso em: Acesso em: 19 mai. 2019

POULAIN, Jean-Pierre; PROENCA, Rossana Pacheco da Costa. O espaço social alimentar: um instrumento para o estudo dos modelos alimentares. Rev. Nutr., Campinas, v. 16, n. 3, p. 245256, Sept. 2003. Disponível em:

$<$ http://www.scielo.br/scielo.php?script=sci_arttext\&pid=S1415-

$52732003000300002 \&$ Ing=en\&nrm=iso $>$. Acesso em 10 mar. 2019

VICTORA, Ceres Gomes; KNAUTH, Daniela Riva; HASSEN, Maria de Nazareth. Pesquisa qualitativa em saúde: uma introdução ao tema. Porto Alegre: Tomo Editorial, 2000.

WILLE, Danielle Neugebauer. No Supermercado, “o Segredo é o Carinho": um Estudo sobre Consumo a partir do Rural, Caseiro e Natural em Embalagens de Alimentos. Dissertação (Mestrado em Ciências Sociais), Universidade Federal de Pelotas. 2014.

WOORTMANN, Ellen Fensterseifer. Herdeiros, Parentes e Compadres: colonos do Sul e sitiantes do Nordeste. São Paulo: Hucitec, 1995. 